\begin{tabular}{|l|l|}
\hline & $\begin{array}{l}\text { ATRIUM: JURNAL ARSITEKTUR } \\
\text { ISSN: 2442-7756 E-ISSN: 2684-6918 } \\
\text { atrium.ukdw.ac.id }\end{array}$ \\
\hline
\end{tabular}

\title{
Identifikasi Keragaman Penyediaan Sarana Prasarana pada Perumahan Peri-Urban Kabupaten Sleman
}

| Diterima pada 05-11-2021 | Disetujui pada 11-11-2021 | Tersedia online 30-11-2021 | | DOI https://doi.org/10.21460/atrium.v7i2.159 |

\section{Sekar Ari Utari ${ }^{1}$, Ardhya Nareswari ${ }^{2}$}

1, 2. Magister Arsitektur, Fakultas Teknik, Universitas Gadjah Mada

Jl. Grafika No.2, Senolowo, Sinduadi, Kec. Mlati, Kabupaten Sleman, Daerah Istimewa Yogyakarta Email: arisekar92@gmail.com

\begin{abstract}
Abstrak
Pengadaan sarana-prasarana perumahan telah diatur melalui SNI 03-1733-2004. Namun di lapangan developer memiliki pertimbangan serta kreatifitas tersendiri dalam penyediaannya. Keragaman penyediaan memunculkan masalah pemerataan akses masyarakat terhadap sarana-prasarana. Penelitian ini bertujuan untuk mengidentifikasi keragaman penyediaan sarana-prasarana perumahan di Kabupaten Sleman. Penelitian menggunakan metode deduktif-kualitatif. Analisis dilakukan melalui tahapan pengelompokan data, analisis tipe perumahan, analisis ketersediaan sarana-prasarana dan analisis perbandingan. Hasil penelitian menunjukkan perbedaan penyediaan pada tipe perumahan skala kecil dan skala sedang. Saranaprasarana dasar menjadi prioritas utama dan sarana prasarana keamanan menjadi prioritas kedua. Variasi didapat pada sarana-prasarana amenitas dan kesehatan dan yang paling sedikit disediakan yaitu sarana ibadah dan pendidikan.
\end{abstract}

Kata kunci: sarana-prasarana, perumahan, Kabupaten Sleman.

\begin{abstract}
Title: Diversity Identification of Infrastructure Provision in Peri-Urban Housing Sleman Regency

The procurement of housing infrastructure has been regulated through SNI 03-1733-2004. However, in the field, developers have their own considerations and creativity in providing them. The diversity of provision raises the problem of equal public access to infrastructure. This study aims to identify the diversity of housing infrastructure provision in Sleman Regency. The research used deductive-qualitative method. The analysis was carried out through the stages of data grouping, housing type analysis, analysis of infrastructure availability and comparative analysis. The results showed different provision between small-scale and medium-scale housing. Basic infrastructure is the top priority and security infrastructure is the second priority. Variations are found in amenities and health facilities and the least provided are religious and educational facilities.
\end{abstract}

Keywords: infrastructure, housing, Sleman regency. 


\section{Pendahuluan}

Dinamika perkembangan perkotaan di dunia selama beberapa dekade terakhir sangatlah pesat. Arus Urbanisasi yang tinggi menyebabkan bertambahnya jumlah penduduk secara eksponensial di kawasan perkotaan. Pembangunan kota dipengaruhi oleh meningkatnya populasi dan kebutuhan perumahan (UN Habitat, 2020). Bertambahnya jumlah penduduk perkotaan, negaranegara di dunia akan menghadapi sejumlah tantangan di dalam penyediaan kebutuhan penduduknya, termasuk kebutuhan terhadap perumahan, infrastruktur, transportasi, energi, pelayanan kesehatan dan pendidikan, dan lapangan pekerjaan.

Ketertarikan masyarakat untuk berduyun-duyun tinggal di kota bukan tanpa alasan. Bagi penduduk yang berasal dari dalam kota, wilayah pinggiran kota merupakan daerah yang sangat menarik untuk dijadikan tempat tinggal karena menawarkan suasana perdesaan, lingkungan alami, lingkungan budaya dan masyarakat perdesaan yang tradisional dan ramah.

Menurut Yunus (2008), terdapat beberapa faktor yang menjadi pemicu penduduk dari kota merasa tertarik dengan wilayah pinggiran kota antara lain: (1) keinginan untuk memperoleh lokasi tempat tinggal yang dekat dengan tempat kerja; (2) keinginan untuk memperoleh peluang kerja yang lebih besar; (3) keinginan untuk menikmati fasilitas kehidupan dan kegiatan yang lebih lengkap; (4) keinginan untuk memperoleh lokasi tempat tinggal yang mempunyai aksesibilitas tinggi; (5) keinginan untuk memperoleh lokasi yang lebih prestisius/lebih bermartabat.

Seperti halnya di kota-kota besar lainnya di Indonesia, fenomena persebaran perumahan ke area pinggiran kota atau seringkali disebut dengan wilayah peri-urban tersebut juga terjadi di Kabupaten Sleman. Sebagai wilayah kabupaten yang berhimpit langsung dengan Kawasan Perkotaan Yogyakarta, Kabupaten Sleman menampung luberan dari Kota Yogyakarta.

Pada kondisi pengembangan perumahan di kawasan peri-urban yang dilakukan oleh pengembang, tingginya pembangunan perumahan sering tidak selaras dengan pemerataan ketersediaan sarana-prasarana (Okoro, Musonda, \& Agumba, 2016). Semestinya pengembang selain memiliki kewajiban untuk memperoleh berbagai macam perizinan, juga memiliki kewajiban untuk menyediakan fasilitas umum dan fasilitas sosial sesuai dengan ketentuan yang disepakati bersama dengan pemerintah daerah melalui penyusunan dokumen siteplan sebagai syarat utama. Fasilitas umum dan fasilitas sosial pada perumahan harus terjaga ketersediaan, fungsi, dan keberlanjutannya agar kualitas perumahan dapat terjaga dengan baik dan tidak menimbulkan kawasan kumuh (Badan Perencanaan Pembangunan Daerah Kabupaten Sleman, 2020).

Dinamika perkembangan Kabupaten Sleman tentunya menjadi magnet daya tarik bagi pengembang perumahan untuk membangun perumahanperumahan di wilayah tersebut namun di sisi lain juga dapat menimbulkan permasalahan keruangan kota. Swasto (2008) mengemukakan bahwa dampak keruangan kota terjadinya perumahanperumahan dengan bentuk cluster (enclave) yang kemudian membebani lingkungan karena tidak diintegrasikan 
dengan kondisi sebelumnya dapat mendorong perubahan fungsi disekitarnya. Maraknya pembangunan yang umumnya tertutup dengan akses terbatas ke dalam lingkungan perumahan (misalnya menggunakan tipe cul de sac, sistem portal tertutup, dan lain sebagainya) serta fasilitas umum maupun sosial yang disediakan secara terbatas dengan kadang-kadang fasilitas ini 'dibebankan' kepada lingkungan sekitarnya merupakan permasalahan yang perlu diantisipasi. Apabila menilik hal tersebut, minat developer untuk terus membangun perumahan di Kabupaten Sleman secara tidak langsung menimbulkan permasalahan pemerataan akses masyarakat terhadap sarana prasarana yang menjadi prioritas pembangunan pemerintah.

Pada dasarnya peraturan tentang pengadaan sarana-prasarana lingkungan telah diatur lewat SNI 03 17332004 tentang tata cara perencanaan lingkungan perumahan. Namun kenyataan di lapangan menjadi berbeda, developer memiliki kebebasan, pertimbangan serta kreatifitas tersendiri dalam memilih fasilitas apa saja yang disediakan pada perumahan yang mereka tawarkan. Setiap developer memiliki sejumlah pertimbangan yang berbeda sebagai preferensinya dalam menyediakan sarana prasarana perumahan.

Penelitian bertujuan untuk mengetahui kondisi di lapangan untuk mengidentifikasi kecenderungan penyediaan sarana prasarana perumahan oleh developer/ pengembang di kawasan peri-urban Kabupaten Sleman. Identifikasi keragaman diharapkan dapat memberikan kontribusi pada penataan keruangan kota. Secara garis besar penelitian ini diharapkan menjadi landasan kontrol terhadap penyediaan sarana prasarana perumahan yang ada.

\section{Metode}

Rancangan penelitian yang digunakan dalam penelitian ini yaitu deduktif kualitatif. Metode tersebut digunakan untuk mengetahui kecenderungan keragaman penyediaan prasarana, sarana, dan utilitas oleh pengembang perumahan di kabupaten Sleman dengan melihat dari ketersediaan atau perbedaan prasarana, sarana, dan utilitas antara rumah besar dan rumah kecil serta rumah sederhana, menengah, dan mewah. Proses pengumpulan data dilakukan melalui tahapan studi literatur, data sekunder dan observasi lapangan. Data yang diperoleh meliputi data dokumentasi foto dan data siteplan. Sampel perumahan berjumlah 60 listing perumahan dari populasi 186 perumahan yang memperoleh ijin dari DPMPPT Kabupaten Sleman pada periode tahun pembangunan 2015 sampai dengan 2020. Peta Sebaran Sampel dapat dilihat pada Gambar 1.

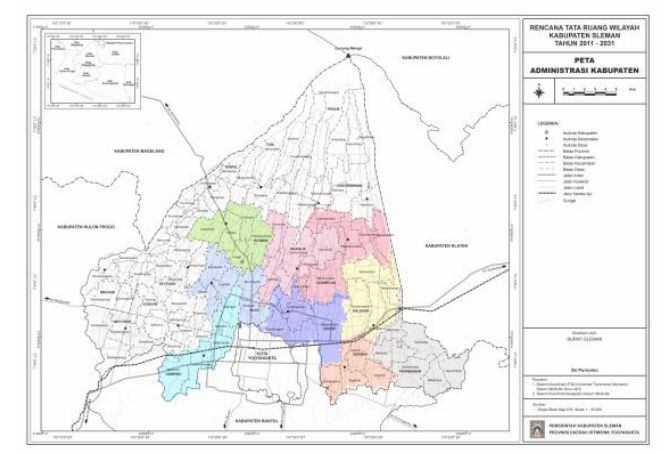

Gambar 1. Peta Sebaran Sampel Penelitian Sumber: Analisis penulis, 2021

Sampel Perumahan tersebar pada 8 Kecamatan yaitu Kecamatan Sleman, Gamping, Mlati, Ngaglik, Depok, Ngemplak, Kalasan dan Berbah. Tahapan analisis yang dilakukan 


$\begin{array}{llll}\text { melalui } 4 & \text { tahapan } & \text { yaitu } & \text { perumahannya. Analisis perbandingan } \\ \text { pengorganisasian data } & \text { yaitu } & \text { dilakukan } & \text { untuk melihat } \\ \text { pengelompokkan data, analisis tipe } & \text { kecenderungan keberagaman dengan } \\ \text { perumahan, analisis ketersediaan } & \text { membandingkan tipe perumahan } \\ \text { sarana-prasarana dan analisis } & \begin{array}{l}\text { dengan nilai skor ketersediaan sarana } \\ \text { perbandingan. Pengelompokan data }\end{array} & \text { prasarananya serta tipe perumahan } \\ \text { dilakukan dengan mengelompokkan } & \text { berdasarkan tipe rumah dengan } \\ \text { data perumahan berdasarkan analisis } & \text { ketersediaan sarana prasarananya. } \\ \text { yang akan dilakukan. Analisis meliputi } & \text { Komponen variabel difokuskan } \\ \text { analisis tipe perumahan skala kecil dan } & \text { meliputi ketersediaan sarana prasarana } \\ \text { skala sedang, serta analisis perumahan } & \text { dasar, sarana prasarana keamanan dan } \\ \text { berdasarkan tipe rumah yang } & \text { sarana prasarana yang bersifat } \\ \text { disediakan yaitu rumah sederhana, } & \text { amenitas. }\end{array}$
menengah dan mewah dan analisis ketersediaan sarana-prasarana perumahannya.

Analisis tersebut disajikan melalui tabel atau grafik. Pada penelitian ini tabel atau grafik yang disediakan yaitu tabel daftar sampel amatan, diagram perbandingan tipe rumah dengan kelengkapan sarana prasarana, diagram luas lahan dengan ketersediaan sarana prasana, grafik ketersediaan sarana prasarana perumahan. Selanjutnya dilakukan analisis tipe perumahan serta dilakukan pembandingan tipe perumahan dengan analisis aspek ketersediaan sarana-prasarana

\section{Hasil dan Pembahasan}

\section{Gambaran Umum Lokasi Amatan}

Lokasi penelitian berada di kawasan perumahan Peri Urban Kabupaten Sleman. Bagian selatan Kabupaten Sleman berbatasan langsung dengan Kabupaten Bantul dan merupakan kawasan aglomerasi Kota Yogyakarta (http://www.slemankab.go.id/, diakses 21 Oktober 2021). Daftar sampel yang menjadi unit amatan dapat dilihat pada Tabel 1. 
Tabel 1. Daftar Sampel Amatan

\begin{tabular}{|c|c|c|c|c|}
\hline No & Kecamatan & Perumahan & Pengembang & Luas \\
\hline 1 & BERBAH & Mukti Sendangtirto Residence & PT Mugi Mukti Mulia & 0,30 \\
\hline 2 & DEPOK & Villa Bougenville & PT Tunggal Putra Bahagia Sejahtera & 1,00 \\
\hline 3 & DEPOK & Grand Ambarukmo & PT Cakrawala Metrik & 0,29 \\
\hline 4 & DEPOK & Vasana Residence & Damai Putra Group & 8,00 \\
\hline 5 & DEPOK & Calm Maguwo Town House & PT Karya Sehati Utama & 0,37 \\
\hline 6 & DEPOK & Greenland Permata & PT Dwi Mitra Intitama & 0,27 \\
\hline 7 & DEPOK & Maguwo Regency & Putera Sakti & 0,25 \\
\hline 8 & DEPOK & Hyarta EcoVIllage & PT Darsana Tempa Internasional & 5,00 \\
\hline 9 & DEPOK & Azalea Citra & PT Citra Kedaton & 0,35 \\
\hline 10 & DEPOK & Arya Green Maguwoharjo & PT Brantas Abipraya & 0,70 \\
\hline 11 & GAMPING & Metro Harmony Ambarketawang & PT Gerbang Madani Group & 0,73 \\
\hline 12 & GAMPING & Lembayung Residence & PT Nirmana Utama & 1,00 \\
\hline 13 & GAMPING & Aruna Citra & PT Citra Kedaton & 0,45 \\
\hline 14 & GAMPING & Quaress Vellas & Quares Group & 0,40 \\
\hline 15 & GAMPING & Kuantan Regency Nogotirto & Merapi Arsita Graha & 1,50 \\
\hline 16 & GAMPING & Pondok Permai Tata Bumi & PT Sumber Baru Land & 0,70 \\
\hline 17 & GAMPING & Villa Green Madani Balecatur & PT Wira Madani Wirasetya & 0,87 \\
\hline 18 & GAMPING & Citra Grand Mutiara & Ciputra Development & 10,00 \\
\hline 19 & GAMPING & Arsita Regency Titi Bumi & Merapi Arsita Graha & 0,30 \\
\hline 20 & GAMPING & Graha Nuansa Citra & PT Diamor Karya Abadi & 0,52 \\
\hline 21 & GAMPING & Ghara Jingga Residence & PT Nirmana Utama & 0,60 \\
\hline 22 & GAMPING & Bukit Mutiara Residence & PT Karya Jaya Abadi Propertindo & 0,85 \\
\hline 23 & GAMPING & Kuantan Regency Kwarasan & PT Merapi Arsita Graha & 0,74 \\
\hline 24 & KALASAN & Tyaga Residence & PT. Bumyagara Balawan Kalyana & 0,50 \\
\hline 25 & KALASAN & Agatama Residence & PT Agatama Putra & 0,42 \\
\hline 26 & KALASAN & Adara Citra & PT Citra Kedaton & 0,50 \\
\hline 27 & KALASAN & Grand Residence Adisucipto & PT Rizki Rahmat Manunggal & 0,39 \\
\hline 28 & KALASAN & Arya Green Kalasan & PT Brantas Abipraya & 0,70 \\
\hline 29 & KALASAN & Griya Purwo Indah & PT Nurma Mandiri Lestari & 0,60 \\
\hline 30 & KALASAN & Royal Maguwo & PT Saraswanti Hasil Makmur & 2,20 \\
\hline 31 & KALASAN & Pondok Permai Bandara & PT Sumber Baru Land & 1,00 \\
\hline 32 & MLATI & Mukti Sendangadi Residence & PT Mugi Mukti Mulia & 0,90 \\
\hline 33 & MLATI & Grand Mlati & PT Karya Sehati Utama & 0,60 \\
\hline 34 & MLATI & Pesona Residence & PT Cahyo Griya Inti Sentosa & 0,56 \\
\hline 35 & MLATI & Bale Mulia & Formula Land & 9,00 \\
\hline 36 & MLATI & The Paradise & PT Sarana Anugerah Pratama & 7,00 \\
\hline 37 & MLATI & Kuantan Square Mlati & Merapi Arsita Graha & 0,60 \\
\hline 38 & MLATI & Grand Tlogoadi & PT Karya Sehati Utama & 4,50 \\
\hline 39 & MLATI & Balegong Residence & PT Tiga Beringin Sejahtera & 0,36 \\
\hline 40 & MLATI & Villa Bahagia Sejahtera & PT Tunggal Putra Bahagia Sejahtera & 0,87 \\
\hline 41 & MLATI & Bale Wangsa & PT Formula Land & 2,20 \\
\hline 42 & NGAGLIK & Green Hills Residence & Damai Putra Group & 8,00 \\
\hline 43 & NGAGLIK & Pastika Palagan Residence 2 & PT Aryaguna Putra & 0,34 \\
\hline 44 & NGAGLIK & Pelangi Mas Residence & PT Yusan Nindyakarsa & 0,56 \\
\hline 45 & NGAGLIK & Ndalem Andaru Banteng & Trah Propertindo & 0,22 \\
\hline 46 & NGAGLIK & Pondok Permai Kaliurang 2 & PT Sumber Baru Land & 0,60 \\
\hline 47 & NGAGLIK & Taman Palagan Asri 3 & PT Roda Pembangunan Jaya & 4,50 \\
\hline 48 & NGAGLIK & Banteng Town House & PT Agatama Puta & 0,20 \\
\hline 49 & NGAGLIK & Pondok Permai Palagan 3 & PT Sumber Baru Land & 0,23 \\
\hline 50 & NGAGLIK & Josari Residence & PT Jogja Griya Sejahtera & 0,28 \\
\hline 51 & NGAGLIK & Pondok Permai Palagan 4 & PT Sumber Baru Land & 0,75 \\
\hline 52 & NGAGLIK & Mukti Sukoharjo Residence & PT Mugi Mukti Mulia & 0,50 \\
\hline 53 & NGEMPLAK & Kanaya Residence Maguwoaharjo & PT Mugi Mukti Mulia & 0,24 \\
\hline 54 & NGEMPLAK & House of Tajem & PT Utama Jaya Mekar & 0,28 \\
\hline 55 & NGEMPLAK & Metro Harmony Wedomartani & PT Gerbang Madani Group & 0,50 \\
\hline 56 & NGEMPLAK & Twin Pine Residence & PT Aneka Gita Karya Sejahtera & 0,57 \\
\hline 57 & NGEMPLAK & Kaliurang Residence & PT Pembangunan Damai Makmur & 0,17 \\
\hline 58 & NGEMPLAK & Orizya Village & PT Citra Anugerah Berkat Utama & 0,36 \\
\hline 59 & NGEMPLAK & Hara Residence & PT Cakrawala Metrik & 0,32 \\
\hline 60 & SLEMAN & Paragon Village & SMD Group & 0,36 \\
\hline
\end{tabular}

Sumber: Analisis Penulis, 2021

Perumahan di Kabupaten Sleman secara umum didominasi oleh perumahan dengan tipe lahan kecil dan sedang. Sementara tipe penyediaan perumahannya merata dari tipe rumah sederhana, menengah maupun mewah. 


\section{Variabel Ketersediaan Sarana Prasarana}

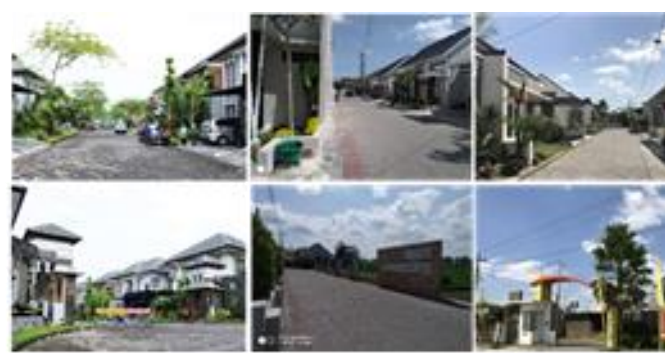

Gambar 2. Sarana Prasarana Perumahan di Kabupaten Sleman

Sumber: Dokumentasi Penulis, 2021

Undang-undang Nomor 1 Tahun 2011 yang mengatur tentang perumahan dan permukiman mendefinisikan perumahan sebagai kelompok rumah yang berfungsi sebagai lingkungan tempat tinggal atau lingkungan hunian yang dilengkapi dengan saranaprasarana lingkungan. Penyediaannya telah diatur secara lebih terperinci sesuai pada SNI 03-1799-2004 (Badan Standarisasi Nasional, 2004). Adapun dua poin peraturan di atas menurunkan variabel amatan pada penelitian ini.

Jenis sarana prasarana yang diamati terdiri dari tiga sarana prasarana yaitu sarana prasarana dasar yang terdiri dari jalan (ketersediaan sarana jalan), air/drainase (ketersedian saluran drainase dan instalasi (underground), lampu dan kelistrikan, RTH/ ruang terbuka hijau, sarana ibadah (ketersediaan sarana ibadah), sarana kesehatan (jogging track, kolam renang, lapangan olahraga, fitness center), dan sarana Pendidikan (ketersediaan sarana pendidikan).

Aspek keamanan dilihat pada variabel kedua mengenai sarana-prasarana keamanan. Manifestasi aspek keamanan didapat dari indikator keberadaan sarana berupa gerbang perumahan (ketersediaan gerbang), pos penjaga/security (ketersediaan pos), pagar/tembok pembatas (ketersediaan pagar pembatas), pagar/tembok menyeluruh (ketersediaan pagar menyeluruh), CCTV (ketersediaan CCTV), dan one gate system (siteplan kuldesak/one gate system).

Aspek ketiga sarana prasarana amenitas yang terdiri dari rekreasi/playground (ketersediaan playground), clubhouse/balai pertemuan (ketersediaan clubhouse), dan komersial (ketersediaan fasilitas komersial). Ketersediaan daftar sarana-prasarana di atas akan dijadikan sebagai indikator nilai kelengkapan infrastruktur perumahan yang diamati.

\section{Variasi Perbandingan Tipe Rumah dengan Kelengkapan Sarana Prasarana}

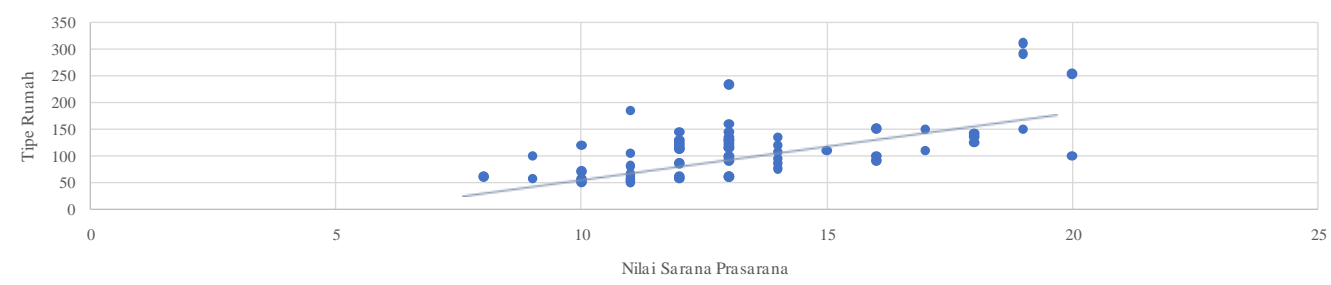

Gambar 3. Perbandingan Tipe Rumah dengan Kelengkapan Sarana Prasarana Sumber: Analisis peneliti, 2021 
Berdasarkan indikator-indikator ketersediaan didapatkan skor yang kemudian diolah menjadi diagram sebar/scatter diagram. Pada Diagram.1 di atas data tersebar dan mengalami kenaikan sehingga menunjukan bahwa data yang digunakan pada scatter tersebut memiliki hubungan positif artinya semakin besar tipe rumah yang disediakan maka meningkat pula jumlah penyediaan sarana prasarana perumahannya. Hal ini didukung dengan penelitian sebelumnya menurut Nurdiansyah (2021), dalam penelitiannya menemukan bahwa terdapat hubungan antara tipe rumah terbesar dan kelengkapan infrastruktur adalah searah (positif) yang berarti jika nilai tipe rumah diperbesar maka nilai kelengkapan infrastruktur akan semakin besar begitupun sebaliknya jika nilai tipe rumah diperkecil maka nilai kelengkapan infrastruktur semakin kecil. Hal ini berarti teridentifikasi keberagaman penyediaan sarana-prasarana perumahan berkaitan antara tipe rumah terbesar dengan ketersediaan jumlah sarana-prasarana perumahannya.

\section{Variasi Perbandingan Luas Lahan dengan Ketersediaan Sarana Prasarana}

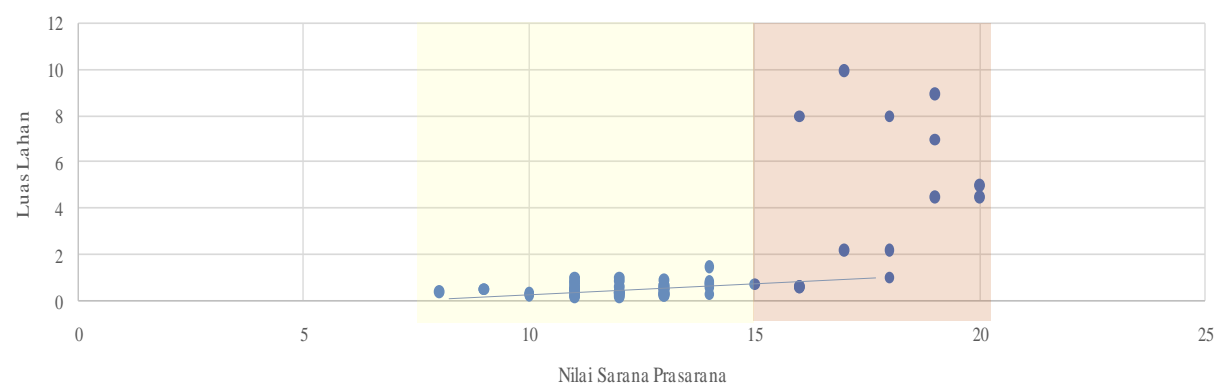

Gambar 4. Luas Lahan dengan Ketersediaan Sarana Prasarana Sumber: Analisis peneliti, 2021

Pada Gambar 4 data tentang perbandingan Luas Lahan dan Ketersediaan Sarana Prasarananya dapat terlihat data tersebar dan mengalami kenaikan sehingga menujukan bahwa dua komponen tersebut memiliki hubungan positif (korelasi positif). Dari diagram scatter tersebut dapat diketahui bahwa hubungan keterkaitan luas lahan dengan jumlah sarana prasarana baik tipe rumah besar maupun luas lahan memiliki hubungan positif seiring dengan bertambahnya luasan maka kecenderungan jumlah sarana prasarananya meningkat. Penyediaan sarana prasarana perumahan di Sleman juga cenderung berkaitan antara luas lahan dan nilai score ketersediaan sarana-prasarananya. Selain itu ternyata kita dapat melihat sebaran ketersediaan sarana-prasarana yang cenderung rapat dan sama pada lahan yang kecil dengan luasan $<2 \mathrm{Ha}$. Sedikit berbeda dengan perumahan luas lahan kecil, pada perumahan yang lebih luas dapat kita lihat developer cenderung memiliki variasi penyediaan sarana prasarana tersebut sangat beragam. Disparsitas data dominan terlihat pada penyediaan saranaprasarana pada luasan lahan di atas 2 Ha dimana jarak sebaran dan nilai ketersediaan menjadi lebih beragam.

Kecenderungan Penyediaan Sarana Prasarana Perumahan oleh Pengembang

Disparsitas keberagaman data dari Gambar 3 dan Gambar 4 diatas dapat 
dijelaskan lebih lanjut melalui Grafik 1 yang menjelaskan mengenai ketersediaan sarana prasarana. Berdasarkan hasil penelitian pada Grafik 1, ketersediaan sarana prasarana perumahan Peri-Urban Kabupaten Sleman dapat diketahui bahwa jenis fasilitas yang tersedia paling banyak adalah jalan, air, lampu penerangan dan telepon yang disediakan pada semua perumahan, sedangkan jenis fasilitas yang tidak tersedia adalah pendidikan yaitu dengan total tersedia.

\section{Grafik 1. Ketersediaan Sarana Prasarana Perumahan}

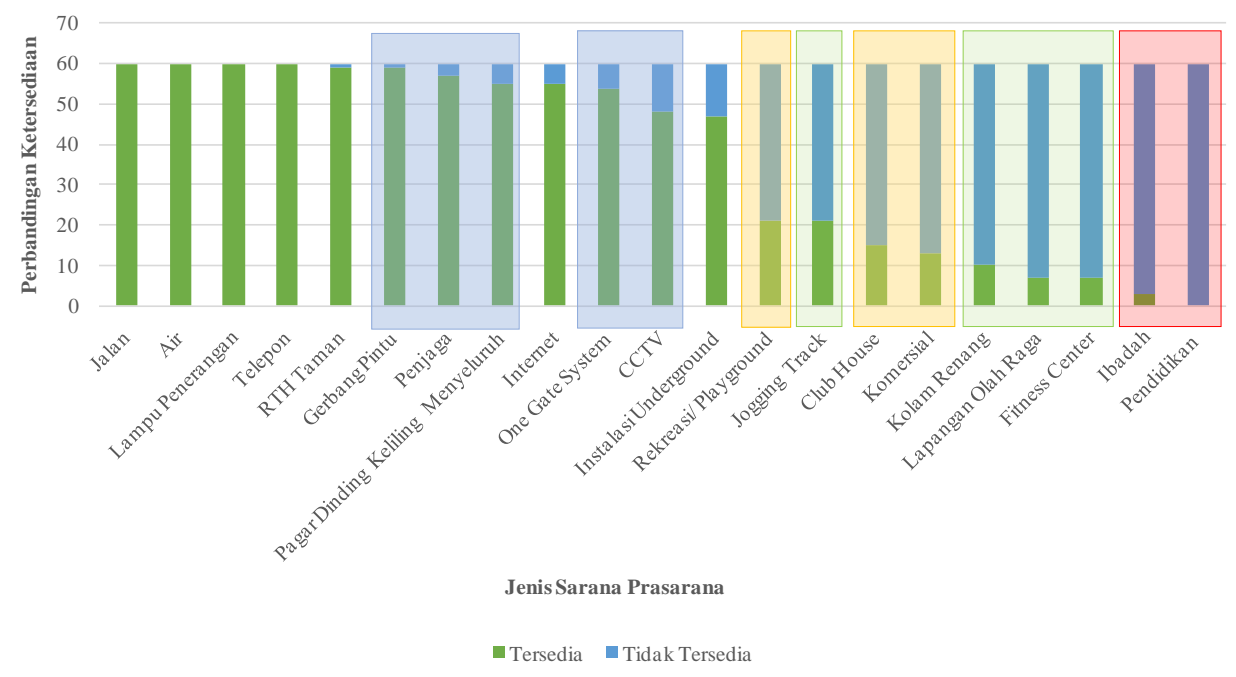

Sumber: Analisis peneliti, 2021

Dari hasil analisis di atas ditemukan bahwa pengembang lebih memprioritaskan meliputi pembangunan sarana prasarana dasar terkait dengan penyediaan jalan air instalasi underground, lampu penerangan telepon internet, RTH taman. Sarana prasarana terkait Kesehatan yang masuk ke dalam sarana prasarana dasar hadir melalui penyediaan fasilitas olahraga. Sarana kesehatan yang seringkali disediakan berupa jogging track pada urutan pertama, diikuti dengan penyediaan kolam renang, lapangan olahraga dan fitness center.

Adapun sarana prasarana yang menyangkut keamanan pengembang memprioritaskan one gate system, keberadaan pagar, gerbang pintu, gerbang penjaga, dan CCTV. Tingginya pemenuhan aspek sarana- prasarana tersebut selaras dengan trend perumahan yang ada di Indonesia yang mengarah pada komunitas berpagar/gated-community. Komunitas berpagar muncul dari "culture of fear" atau budaya rasa takut dari komunitas urban menengah atas terhadap berbagai macam tindak kriminal (Smith-Bowers \& Manzi, 2006). Tingginya penyediaan sarana-prasarana juga selaras dengan pendapat Swasto (2008) yang mengemukakan kecenderungan pembangunan yang umumnya tertutup dengan akses terbatas ke dalam lingkungan perumahan yang berdampak pada ketimpangan dan keterbatasan akses baik dari perumahan maupun ke dalam perumahan.

Tren eksklusifitas juga nampak dengan variasi penyediaan banyak didapatkan pada sarana-prasarana yang berkaitan dengan sarana-prasarana yang bersifat 
amenitas seperti tempat rekreasi dan juga sarana prasarana yang menunjang kesehatan seperti fasilitas olahraga. Blakely dan Snyder (1998) mengklasifikasikan komunitas yang terjaga keamanannya di AS ke dalam zona gaya hidup, prestise dan keamanan. Penekanan pada nilai keamanan dan amenitas menjadi bukti sebuah gated community di Indonesia merupakan kombinasi dari ketiganya. Berdasarkan data perilaku pengembang menunjukkan bahwa selain aspek sosial ekonomi, masalah keamanan menjadi kepentingan pembangunan, tetapi prestise dan gaya hiduppun penting (Leisch, 2002).

Sarana prasarana yang terkait dengan amenitas dapat dilihat dengan penyediaan sarana rekreasi dan playground, balai pertemuan/clubhouse serta fasilitas komersial. Fasilitas komersial disediakan dengan pengadaan integrasi antara perumahan dan pertokoan/rumah toko. Terdapat 13 perumahan dari 60 sampel perumahan yang melakukan integrasi antara rumah tinggal dan sarana komersial. Sementara itu dua poin terendah yang berada paling akhir dari list prioritas pengembang adalah sarana ibadah dan juga sarana pendidikan. Sarana ibadah hanya ditemukan pada 3 dari 60 perumahan selain fasilitas-fasilitas di atas semestinya terdapat fasilitas yg berkaitan dengan sarana pendidikan namun pada kenyataan di lapangan dari 60 sampel yang ada tidak ada satupun perumahan yang menyediakan sarana pendidikan.

Keberagaman variasi dan tipe penyediaan pada data penelitian yang ada tentunya perlu digaris bawahi. Selain penekanan pada aspek sarana prasarana yang mendasar maupun berhubungan dengan keamanan dan amenitas, pembangunan dan konstruksi berkelanjutan dari perumahan semestinya mengacu pada aspek ekonomi, ekologi, dan isu-isu sosial suatu infrastruktur dalam konteks komunitasnya (Diah et al., 2019). Salah satu kriteria kinerja pembangunan semestinya juga mempertimbangkan tidak hanya kinerja dalam hal keselamatan (safety) dan kesehatan (health). Perencanaan berkelanjutan harus diterapkan pada perumahan dan urbanisasi dengan tujuan untuk menghindari dampak buruk terhadap lingkungan dan memperoleh manfaat sosial, ekonomi dan lingkungan yang maksimal bagi semua, benefits for all.

\section{Kesimpulan}

Berdasarkan paparan di atas dapat dilihat bahwa betul adanya keberagaman penyediaan saranaprasarana perumahan yang ada di Kabupaten Sleman. Pengembang cenderung memiliki perilaku yang berbeda dalam menyediakan fasilitas perumahan pada tipe perumahan dengan luas lahan skala kecil dengan luas lahan skala sedang. Begitu pula dapat dilihat perilaku yang berbeda dari pengembang dalam menyediakan sarana-prasarana pada perumahan sederhana, menengah dan mewah.

Meskipun begitu ditemukan ragam variasi penyediaan perumahan memiliki poin prioritas penyediaan yang hampir sama. Dimana pengembang secara umum memprioritaskan sarana-prasarana dasar pada perumahan berupa jalan, air, listrik berikut lampu penerangan, telepon dan RTH taman. Sarana Prasarana Keamanan menjadi prioritas kedua, dimana dapat dilihat pada Grafik.1 yang meliputi penyediaan gerbang, sistem siteplan kuldesak/one 
gate system, pagar dinding baik sebagian maupun menyeluruh maupun CCTV. Prioritas pengadaan sarana prasarana keamanan selaras dengan trend perumahan di Indonesia yang mengarah pada gated community yang menciptakan pagar segregasi terhadap akses sarana-prasarana. Sarana prasarana yang kurang diprioritaskan oleh pengembang terdiri dari saranaprasarana ibadah dan pendidikan.

Secara garis besar lewat paparan data dalam penelitian ini dapat dilihat bahwa meskipun dibutuhkan dan diatur dalam SNI tetapi tidak semua jenis sarana-prasarana perumahan disediakan oleh pengembang. Pengembang memiliki prioritas dan juga kreatifitas dalam menyediakan sarana prasarana perumahan. Penelitian terkait dengan kualitas dari penyediaan saranaprasarana di Peri-Urban Kabupaten Sleman dapat dilakukan di masa yang akan datang untuk melengkapi penelitian ini.

\section{Ucapan Terima Kasih}

Tiada gading yang tak retak, semoga tulisan ini dapat memberikan manfaat dan tak lupa penulis haturkan terimakasih yang tak terhingga kepada pihak-pihak terkait yang telah membantu menyusun penelitian ini sampai dengan selesai dan Redaksi Atrium yang telah berkontribusi mereview jurnal ini.

\section{Daftar Pustaka}

Badan Standarisasi Nasional. (2004). Tata cara perencanaan lingkungan perumahan di perkotaan. (SNI 03-1733-2004). Jakarta: Badan Standarisasi Nasional.
Badan Perencanaan Pembangunan Daerah Kabupaten Sleman. (2020, November 26). Prasarana dan sarana umum perumahan untuk masyarakat: sebuah proses serah terima PSU dari developer kepada pemerintah daerah. https://bappeda.slemankab.go.id/ prasarana-dan-sarana-umumperumahan-untuk-masyarakatsebuah-proses-serah-terima-psudari-developer-kepadapemerintah-daerah.slm

Blakely, E.J., Snyder, M.G. (1998). Separate places: crime and security in gated communities. pp. 53-70. Washington, D.C.: Urban Land Institute.

Diah, N.M., Kusumo, B.B.P., Tri, S. (2019) Factors influencing safety and health performance for low cost housing: developer's perspective. Eurasia: Economics \& Business, Vol. 20, 66-73. DOI https://doi.org/10.18551/econeura sia.2019-02.

Leisch, H. (2002) Gated communities in Indonesia. Cities, Vol. 19, 341350 .

Nurdiansyah, A.J. (2021). Keterkaitan tipe rumah dengan kelengkapan infrastruktur pada gatedcommunity di peri-urban (studi kasus: Kabupaten Bandung). (Tesis S2, Institut Teknologi Bandung, 2021. Tidak dipublikasikan).

Okoro, C.S., Musonda, I., Agumba, J. (2016). Identifying Barriers to Urban Residential Infrastructure Development: a Literature Review. In C. Aigbavboa \& W. Thwala (Eds.), International Conference on Infrastructure Development in Africa (p. 468).

Putri, H.T., Maryati, S. (2018). Prioritas penyediaan infrastruktur dasar oleh pengembang 
perumahan di kecamatan parongpong Kabupaten Bandung Barat. Plano Madani, Vol. 7, 1223.

Smith-Bowers, B., Manzi, T. (2006). Private security and public space: new approaches to the theory and practice of gated communities. European Journal of Spatial Development, Vol. 19, 341-350.

Swasto. D.F. (2008). Pergeseran tren: pasar vs permintaan analisis kecenderungan dan dampaknya di Yogyakarta. Proceedings Seminar Nasional Eco-Urban Design: Potensi \& Tantangan Perencanaan Kota Kota
Indonesia di Masa Mendatang, Semarang: 23 Oktober 2008. Hal. 48-50.

UN-HABITAT. (2019). The state of the world's cities report 2006/2007- the millennium development goals and urban sustainability: 30 years of shaping the habitat agenda. London: Earthscan.

Yunus, H. S. ( 2008). Dinamika Wilayah Peri-Urban: Determinan Masa Depan Kota. Yogyakarta: Pustaka Pelajar. 